\title{
O ESPAÇO NA LITERATURA E O ESPAÇO DA LITERATURA
}

\author{
Conceição Aparecida Bento*
}

\begin{abstract}
Resumo: Este artigo analisa o espaço literário a partir de duas vertentes: o espaço na literatura e o espaço da literatura. A primeira vertente incide sobre a presença do espaço escolar nos romances O Ateneu, de Raul Pompéia, e Madame Bovary, de Gustave Flaubert. Na obra de Pompéia, esse espaço domina; na de Flaubert, ele está na cena inicial de apresentação da personagem Charles Bovary e na explicitação da formação de Ema. A segunda vertente parte dessas análises e discute a possibilidade de explicitação do ser da literatura.
\end{abstract}

Palavras-chave: Literatura; espaço; escola.

Abstract: This article analyses the literary space from two aspects: the space in literature and the space of literature. The first aspect concentrates upon the presence of the school space in the novels O Ateneu, by Raul Pompéia, and Madame Bovary, by Gustave Flaubert. In Pompéia's work, this space dominates; in Flaubert's, it is both in the initial scene of presentation of the character Charles Bovary and in the explanation of the formation of Ema. The second aspect starts from these analyses and discusses the possibility of explanation of the existence of literature.

Keywords: Literature; space; school.

* Universidade Federal dos Vales do Jequitinhonha e Mucuri. 
"Vais encontrar o mundo, disse-me meu pai, à porta do Ateneu. Coragem para a luta." A exortação lança Sérgio no espaço escolar e inicia o romance de Raul Pompéia. O internato é a fonte das experiências do jovem num texto que mescla a aprendizagem à dor e à perda das "ilusões da criança educada exoticamente na estufa de carinho que é o regime do amor doméstico" (POMPÉIA, 1981, p. 5). A escola antecipa o mundo e é lugar de passagem e de encontro com os dissabores futuros. Sérgio inicia o seu percurso com a notícia do seu desalinho físico; é necessário arranjar o corpo - deitar fora seus cachinhos -, ajustá-lo ao novo espaço e aos desmandos de Aristarco, romper os liames maternos. No texto de Pompéia, um preâmbulo sugere a dimensão espacial da narrativa. O primeiro capítulo apresenta o Ateneu e o prestígio que ele desfruta no império; obra da destreza do diretor, o pedagogo Aristarco, em manipular o reclame junto às famílias ricas de norte a sul do Brasil.

Se nesse romance o leitor é investido de antecipações explícitas sobre o desenrolar da trama, em outro, este se vê lançado no enredo por meio de uma situação escolar. O jovem Charles, de Madame Bovary, chega mal-ajambrado e fora de hora à escola. Sua entrada na sala de aula mostra falta de destreza corporal e linguística: veste-se de modo pouco cômodo e possui uma fala incomum aos seus colegas. Como em Sérgio, há a inadequação física. Diferente de O Ateneu, no entanto, o romance de Flaubert inicia-se com um narrador-testemunha, um nós enigmático englobando um eu que não se explicita: "Nós nos encontrávamos na sala de aula, quando entrou o diretor, acompanhado por um novo aluno, trajado com modéstia, e um servente segurando entre os braços uma grande carteira" (FLAUBERT, 2002, p. 9). Não se identifica o narrador, embora se encontre na cena uma das personagens do enredo subsequente: o jovem Charles Bovary, futuro paramédico e marido de Ema. Na escola e no mundo, Charles personifica o desajuste às expectativas, fato antecipado pela repetição da escrita imposta pelo professor: "vinte vezes o 
verbo ridiculus sum" (FLAUBERT, 2002, p. 11). A injunção e o eu do Ateneu são substituídos, no início do romance de Flaubert, por um nós intrigante - quem narra? - que logo dá lugar ao narrador heterodiegético apresentando as trajetórias de Ema e Charles. O texto, aberto com esse espaço, voltará a ele. Ema, futura madame Bovary, como Sérgio e Charles, encontra o mundo por meio de um local de ensino. O início da formação da personagem se dá pela leitura de romances proibidos, levados para o interior do convento por uma trabalhadora da rouparia protegida do arcebispo. Lendo O Ateneu - "De mão em mão como epístolas, corriam (...) os romances proibidos. Os romances, enredados de atribulações febriciantes, chocantes no desenlace, (...) alguns temperados de grosseira sensualidade" (POMPÉIA, 1981, p. 117) -, encontramos Madame Bovary - "emprestava às mais crescidas alguns romances que levava sempre no bolso do avental (...). Era só amores, amantes, damas perseguidas que desmaiavam em pavilhões solitários" (FLAUBERT, 2002, p. 48).

A escola une as três personagens, lançando-as numa sociabilidade complexa. É um espaço com muitos significados: passagem da esfera doméstica para a pública; distanciamento do eixo familiar; lugar de confronto entre o privado e público; lugar de inscrição no mundo da cultura em oposição ao da natureza; lugar ao qual, inicialmente, deve-se ajustar o corpo. A afirmação do pai, voz pouco presente no romance O Ateneu, associa-o ao mundo. Sérgio colhe os indícios desse universo nas relações de poder e de sedução com os colegas e com os professores, na repressão à sexualidade e na figura do diretor-reclame, vendendo sua pedagogia e adaptando suas ações às conveniências do negócio Ateneu. Um riso irônico, muitas vezes, acompanha a leitura do romance: o leitor reconhece nele os ajustes econômico/ pedagógicos tão em voga nas escolas de hoje. Em Madame Bovary, há implicações, não se leiam determinações, entre a entrada inábil de Charles na sala de aula e o seu futuro, assim como entre as leituras românticas de Ema e o bovarismo porvir. Nos três casos, $O$ 
pretenso espaço humanizador, de ascensão intelectual, é um locus de humilhação, de mercantilizações variadas; enfim, há nele uma aprendizagem às avessas.

A escola diz o mundo nas suas perversões, amalgama uma dimensão preparatória para uma vida de repetições, obediência e supressões de desejos. Assim, o espaço congela o tempo nas ações reiteradas e nos horários pré-organizados. Não é arbitrária a pedagogia da repetição, presente nos dois romances, sobretudo para os recalcitrantes: Charles e os que resistem à ordem no Ateneu devem fustigar os dedos com cópias exaustivas. Esse cronotopo, "interligação fundamental das relações temporais e espaciais" (BAKHTIN, 1993, p. 211), local de coabitação coletiva em que o "Viver-Junto é também temporal" (BARTHES, 2003, p. 11), coaduna-se às organizações espaço-temporais não idílicas. A passagem do espaço familiar para a escola, nesses romances, alude ao distanciamento dos vínculos com a natureza, com as diferentes formas de adesão ao materno e ao natural; enfim, à ruptura com "todo espaço de relações humanas definido por uma ausência de conflito" (BARTHES, 2003, p. 171). Nos romances idílicos, a imobilidade espacial e a estaticidade temporal associamse ao gozo; o "pequeno mundo limitado no espaço se autosatisfaz" (BAKHTIN, 1993, p. 333). As rupturas nesses dois eixos explicam-se pelo acaso, pela Providência, não carecem de nenhuma linha de construção racional.

O espaço, nas concepções de Bakhtin e Barthes, não se caracteriza pela demarcação de uma territorialidade no interior da obra literária, pela delimitação de um elemento da estrutura da narrativa.

O texto do crítico russo, Formas de tempo e de cronotopo no romance, possui como subtítulo Ensaios de poética bistórica, indicativo do viés histórico, da "relativa estabilidade tipológica dos cronotopos dos romances" (BAKHTIN, 1993, p. 212), dos espaços variados no interior da história literária: a estrada, o castelo, o salão, a província entre outros. O salão, o crítico encontra nas obras de 
Balzac e Stendhal; espaço que condensa o traço público e privado e quiçá o tempo ocioso dos seus frequentadores. A província é analisada por meio do romance Madame Bovary, espaço do cotidiano que se junta ao tempo como ícone do ordinário. O espaço nessa concepção enrodilha-se ao tempo; distancia-se da mera concepção de locus do enredo e do enquadre das personagens, perfazendo com esses a estrutura da narrativa e vinculando-se à exterioridade do texto. O viés de interação é interno e externo. Os cronotopos, ligação do espaço-tempo, termo que Bakhtin empresta de Einstein, possuem dimensão social, mas organizam-se de modo diferente a cada obra; associados a uma época, a um momento histórico, só ganham força no caráter interno, escapando-se, dessa forma, de previsibilidades.

Em Como viver junto, de Barthes, o espaço alia-se à sociabilidade, ao viver com o outro. Acompanha a análise a noção de ritmo, indicativa das linhas de forças que atravessam os espaços. A mãe que anda na rua arrastando pela mão a criança impõe a esta um modo de interagir com o espaço e com o tempo. Nos espaços de sociabilidade arvoram-se forças de comando e subjugação. Barthes, na obra, percorre espaços literários: o sanatório, o claustro, a cama, o labirinto, o deserto. Não há menção à escola, embora ela possa associar-se aos espaços preconizadores da formação do indivíduo em meio a regulamentos, ou seja, a ritmos impostos pelo outro.

A sociabilidade dos espaços presentes no interior das obras literárias expande-se, em Barthes e em Bakhtin. O espaço é, assim, relacional, pois implica o social e o histórico; é relacional porque implica a história da literatura e ainda por vincular-se à referência, explícita ou não, a textos literários, nos processos de intertextualidade.

Em OAteneu, a escola inscreve nos meninos a ordem por meio dos horários e das regras que, ironicamente, vigem conforme as circunstâncias. Os conteúdos escolares interessam menos que 
essa inscrição. A luta ${ }^{1}$ se dá entre as exigências desse espaço e os dispositivos psíquicos que desejam uma outra ordem e não a do ambíguo superego bem representado, no texto de Pompéia, por Aristarco. Essa ambiguidade é exemplificada pelo episódio da agressão de Sérgio ao diretor. Não se pune o aluno, pois isso levaria a perdas no já combalido caixa da escola, devido à saída de Bento Alves. "Não valia a pena perder de uma vez dois pagadores prontos, só pela futilidade de uma ocorrência desagradável, (...) mas sem testemunhas." (POMPÉIA, 1981, p. 146). Antes o vacilo das regras, às perdas econômicas.

Em confronto com a ambiguidade dessa moral, há a busca de uma outra ordem: a do corpo e dos seus desejos insurgindo contra as forças que os reprimem. Essa demanda pode ser vista nas reiteradas tentativas dos adolescentes de escapar às determinações, nos estratagemas empregados pelos meninos para se furtarem às regras e na sexualidade que, reprimida, aparece com força nas relações com os colegas e nas figuras femininas de Ângela e Ema. "O erotismo reprimido emerge precisamente do campo dos instrumentos que serviram à sua repressão" (FREUD, 2003, p. 53).

Nos dois romances, a saída da família para a escola indica a passagem para uma outra ordem. Ainda que não se saiba qual o futuro de Sérgio, o tom da narrativa, realizada num presente/ futuro, marcado pelo advérbio boje, sugere a dívida deixada pelos tempos passados no Ateneu:

\footnotetext{
${ }^{1}$ A etimologia permite relacionar a escola à luta: "O nome habitual para a escola grega, junto com didaskálion, que a define por ser o lugar onde se ensina, ou o lugar onde está o mestre, didáskalos, era palaístra, 'palestra', termo que deriva de pále, 'luta'. A associação entre escola e luta, que pode surpreender à primeira vista, faz-se compreender ao se prestar atenção à organização dos estudos na época clássica grega, em que, aos estudos de leituraescrita, aritmética e música, habitualmente pela manhã, seguia-se pela tarde a aula dedicada à ginástica: os ginásios ou palestras." (CASTELLO \& MÁRSICO, 2007, p. 76).
} 
Lembremo-nos, entretanto, com saudades hipócritas, dos felizes tempos; como se a mesma incerteza de boje, sob outro aspecto, não nos houvesse perseguido outrora e não viesse de longe a enfiada de decepções que nos ultrajam. (POMPÉIA, 1981, p. 5)

Não é difícil analisar a escola, tal como se apresenta nesses dois romances, como local de aprendizagem para uma nova ordem social. O início dessa mudança é impreciso; alguns críticos o identificam no fim do século XVIII e começo do XIX. "É preciso encontrar uma nova relação com a natureza, não com a pequena natureza do recanto familiar, mas com a vasta natureza do mundo imenso" (BAKHTIN, 1993, p. 340). Para tanto, "o homem deve educar-se e reeducar-se para a vida nesse mundo vasto e estranho para ele (...). Segundo a definição de Hegel, o romance deve educar o homem para a vida numa sociedade burguesa" (BAKHTIN, 1993, p. 341).

Se o romance deve educar o homem, é compreensível a presença do elemento responsável pela educação como um dos seus espaços. Educar-se é a garantia de conhecer uma etiqueta, de alçar a comportamentos que qualificam o homem nessa ordem.

O espaço presente nos dois romances possui fortes implicações histórico-culturais. Poder-se-iam analisar o papel da escola nos textos literários e a sua importância nos três últimos séculos na formação do ideal de um novo homem. A figura de Aristarco permite vislumbrar os traços do autoritarismo e das conveniências na sociedade brasileira. Ele educa conforme as circunstâncias e o cabedal do aluno. Como afirmou Mario de Andrade, é um dos raros tipos associados à educação presentes na literatura brasileira. Essas possibilidades afirmam esse espaço como relacional. A escola, no interior dos romances, não se fecha sobre si mesma; articula-se à sociedade e inscreve suas regras nos alunos, haja vista o bullying aplicado ao linguajar do campônio, em Madame Bovary, e a humilhação imposta por Aristarco ao aluno que assina com nome feminino um bilhete endereçado ao colega. 
Essa perspectiva de análise vincula a literatura ao mundo no qual ela se insere. É um mundo que se distancia da concepção idílica não é possível a esse novo homem encontrar o acolhimento na calma da natureza. Sérgio, na obra de Pompéia, deve deixar fora da escola os seus cachinhos; em Madame Bovary, o pai de Ema, o velho Rouault, espera que ela se dê bem na vida distanciando-se da lida na terra, "trabalho amaldiçoado pelo céu, pois jamais havia enriquecido ninguém" (FLAUBERT, 2002, p. 22). A salvação, ele encontra em Charles; embora o rapaz lhe parecesse um pouco efeminado, possuía a etiqueta conveniente ao momento: "se portava bem, (...) era econômico, muito instruído." (FLAUBERT, 2002, p. 22).

Se esses romances distanciam-se da dimensão idílica, ela, no entanto, deles se aproxima. Nos dois textos, encontramos, numa outra direção, a sua presença. $O$ idílio está na remissão, nas duas obras, à pastoral de Bernardin de Saint-Pierre. De um lado, essa absorção estende o tempo histórico e o espaço dos dois romances a outros tempos e espaços; de outro lado, abre o texto a um novo espaço. Não mais o topos concreto e circunscrito a que o romance se refere, mas o espaço da linguagem literária, unindo as duas tramas a outras. No início do capítulo em que se apresenta a formação de Ema, o narrador traz à tona suas leituras:

Ema havia lido Paul e Virgínia, tinha sonhado com a cabana de bambus, com o negro Domingos, com o cachorro Fiel, sobretudo com a suave amizade de algum irmãozinho que lhe colhesse frutos maduros em árvores mais altas que as torres de igreja ou que corresse descalço pela areia, para lhe trazer um ninho. (FLAUBERT, 2002, p. 46)

No Ateneu, Sérgio e Egbert também leem Paul et Virginie.

A pastoral de Bernardin de Saint-Pierre foi principalmente o nosso enlevo. Parecia-nos ter o poema no coração. (...) Ideávamos vagamente, mas inteiramente, na mediação sem palavras do sentimento, quadro de manchas sem 
contorno, ideávamos bem as cenas que líamos da singela narrativa, almas que se encontram, dois coqueiros esbeltos crescendo juntos, erguendo aos poucos o feixe de grandes folhas franjadas, ao calor da felicidade e do trópico. (...)

Revíamos o idílio todo, instintivo e puro. (POMPÉIA, 1981, p. 154)

Nesses dois exemplos, a linguagem literária realiza uma auto-fagocitose. Eis uma outra forma de se pensar a relação da literatura com sua história que, não arbitrariamente, é a do mundo. Os dois romances partem da escola, do seu papel e o das leituras como possibilidades de formação e de deformação; os dois romances citam Saint-Pierre e, nisso, reconhecem a literatura como parte do exercício literário. A remissão à história dos dois jovens de Pamplemousses - "Paul et Virginie n'avaient ni horloges, ni almanachs, ni livres de chronologie, d'histoire, et de philosophie. Les périodes de leur vie se réglaient sur celles de la nature"2 (SAINT-PIERRE, 1993, p. 120) - possui um viés intertextual irônico. No interior do mundo não idílico, em meio a artifícios, as personagens sonham com uma vida atrelada à natureza e à ausência de conflitos e, cada vez mais, se distanciam dela; há um descompasso entre a escola, local emblemático nesses romances, as aspirações que ela intenta realizar, os textos que ela comporta e as aspirações criadas nas personagens. A presença da pastoral de Saint-Pierre nos textos é a marca explícita da dissonância entre o artifício da escola e a pedagogia da natureza; a pastoral, no entanto, não está só. Implicitamente, ela evoca Robinson Crusoé e Rousseau.

A intertextualidade associa a mulher de Aristarco à protagonista de Flaubert: ambas reticentes e insatisfeitas com os

2 "Paul e Virginia não possuíam relógios, almanaques, livros de cronologia, de história ou de filosofia. As etapas de suas vidas harmonizavam-se com as da natureza." (Tradução nossa) 
seus maridos; ambas, Emas, anagrama de ame. O fio intertextual prossegue. Madame Bovary lê Walter Scott, inspira-se nas heroínas românticas no seu ensejo de amantes. Na obra de Pompéia, o narrador usa a literatura para tecer considerações sobre si e sobre o outro. Alude ao amor cortês para indicar o seu sofrimento de enamorado pelo colega e, numa espécie de mise en abîme, alude ao casal leitor da Divina comédia ${ }^{3}$ para apresentar a posição dos colegas achincalhados por Aristarco - "Cândido e Tourinho, braço dobrado contra os olhos, espreitavam-se a furto, conformando-se na identidade da desgraça, como Francesca e Paolo no inferno" (POMPÉIA, 1981, p. 147).

As remissões intertextuais permitem pensar um outro espaço, o literário. A ficcionalidade, tenha ou não dimensão autobiográfica, realiza essas remissões e a partir delas projeta outras ficções, matérias para outras intrigas. Dessa forma, o exercício da literatura volta-se sobre si para realizar-se. Nessa reflexibilidade cumulativa de referências a obras anteriores e no exercício das potencialidades da língua, como no caso da ironia, o espaço literário, espaço de difícil explicitação, afirma-se como o da linguagem.

O Ateneu ultrapassa o relato de um menino no internato homônimo, assim como ultrapassa a caracterização de um possível relato autobiográfico. O texto apresenta elementos que problematizam essas especificações. Não se discute aqui a equívoca dissociação entre autobiográfico e ficcional e a relação entre estes e a literatura. O Ateneu faz dessas dimensões, associadas aos dados espaciais e temporais, realizações da

\footnotetext{
${ }^{3}$ No canto V do Inferno da Divina comédia, Francesca relata como sucumbiu ao amor do seu cunhado, Paolo: "Líamos um dia - mero passatempo - o relato de como Lancelote resultara vencido pelo amor. Estávamos sós, desarmados de malícia. Por vezes, nossos olhares, encontrando-se, fizeram suspender a leitura e mudar a cor das faces. Um trecho nos fez sucumbir: ao lermos como a ansiante amada fora beijada pelo febril amante, este que de mim jamais se aparte, todo a tremer, beijou-me a boca. Culpados, pois, o livro e o seu autor - eis que, aquele dia já não lemos mais.” (ALIGHIERI, [s.d.], p. 41)
} 
linguagem. Essa realização não se restringe, entretanto, a um instrumento do dizer; ela se constitui como um dado criador de formas de dizer singulares a cada obra.

O incipit do romance de Pompéia nos dá exemplo. Ele remete à enunciação construída num eixo temporal diferente da dos fatos enunciados. Isso lhe permite preparar o leitor para os elementos subsequentes que, embora no passado, já se contaminam pela enunciação presente que resgata, temporalmente, e antevê, do ponto de vista da narrativa, o peso deixado pela entrada na escola. A discrepância entre a situação do narrador e a do leitor realiza um jogo de expectativas não resolvidas. No trecho já citado da obra de Pompéia (cf. p. 13), último período do primeiro parágrafo do texto - "Lembremo-nos, entretanto, com saudade hipócrita dos felizes tempos; como se a incerteza de hoje, sob outro aspecto, não nos houvesse perseguido outrora" (POMPÉIA, 1981, p. 5) -, o leitor não sabe quais foram os felizes tempos passados e saberá menos ainda sobre as incertezas de hoje, ou seja, desse presente da enunciação. A prolepse desse início insinua antecipações longe de esgotá-las. O leitor, ao longo do texto, percebe essas incertezas no tom adotado pelo narrador. Serão necessários, por exemplo, dois parágrafos com longos períodos cheios de intercalações para que esse narrador, enrodilhado em seus tormentos, chegue a um período simples - "Eu tinha onze anos" (POMPÉIA, 1981, p. 5). Os tormentos concretizam-se no modo de narrar de boje e ligam-se ao tempo passado no Ateneu.

O narrador de Madame Bovary não antecipa. Também no futuro e remetendo ao passado - o uso dos pretéritos imperfeito e perfeito o atesta: "Nós nos encontrávamos na sala de aula, quando entrou o diretor" (FLAUBERT, 2002, p. 9) -, o narrador apresenta a cena. A continuação da leitura permite ao leitor ver o Charles paramédico, indeciso e pouco afeito a atitudes arrojadas, na cópia repetida do verbo latino. Assim, neste caso, é o futuro da leitura e não o da enunciação o dado que permite ver na cena inicial uma antecipação. 
No exemplo dado em $O$ Ateneu, o narrador elabora insinuações e o leitor buscá-las-á no texto; em Madame Bovary, o narrador inicial não suscita nada. Uma vez suprimida essa voz participante da narrativa - nesse intrigante nó do nós -, o leitor, seguindo uma outra voz, estabelecerá as ligações entre as partes do enredo.

Observam-se o trabalho com a linguagem e uma cronotopia em que o tempo e espaço da narração diferenciam-se do tempo e do espaço narrados. A escola e o passado no qual ela se insere estão distantes do presente e do espaço da narração. $O$ desarranjo espaço-temporal está, de modo singular, nos inícios desses dois romances. Ele, todavia, não é nada sem a presença do leitor. $O$ trabalho com a linguagem inexiste na obra sem a leitura. Esse espaço, um dos traços do literário, nada é sem o leitor. Este vai à obra e, com o ato que o define, realiza a existência dela. Assim, a pergunta sobre o espaço literário cruza a linguagem e o leitor. A linguagem não basta para dizer esse espaço, pois ela sem o leitor é morta; não se encontra e não se diz. Deve-se mencionar a necessidade de entrelaçamento entre o leitor e o texto. Isolados, a obra não se constitui.

Dessa forma, o ser da literatura, como uma entidade substancial, dita a priori, não existe. Isso ocorre não só porque há uma dependência do leitor; mas sobretudo porque o trabalho do texto literário com a linguagem furta-se a categorias prédeterminadas. As figuras de linguagem desagregadoras dos sentidos correntes podem inserir-se na literatura, mas não a definem. Podem, dependendo do caso, representar um artificialismo que transforma o texto numa caricatura, tangenciando o pernóstico. A escrita literária não é uma ortopedia; realizá-la não "consiste somente em utilizar as palavras usuais com mais maestria, (...) [não significa] um entendimento mais harmonioso de seus recursos musicais. Escrever jamais consiste em aperfeiçoar a linguagem corrente, em torná-la mais pura" (BLANCHOT, 2011, p. 43). Por isso, pensar o espaço literário talvez seja refletir sobre algumas de suas instâncias caracterizadoras, aceitando, a priori, 
a impossibilidade de dizer o seu ser.

A realização da linguagem no literário escapa a determinações e inscreve-se na singularidade da obra e no exercício da leitura. A sua âncora é a leitura e os entrelaçamentos por ela estabelecidos. Essa é a ação permissiva do ser da literatura; é o espaço de sua realização.

O texto de Pompéia assume como uma das suas marcas as inversões da ordem direta. Os hipérbatos são frequentes no interior da obra, exigem atenção do leitor para que se perceba $o$ foco da construção. Outra exigência soma-se a essa: a percepção da ironia, atravessando os episódios narrados. O texto é um emaranhado de subentendidos, uma pletora de reticências, muitas vezes implícitas. Elas fazem do espaço dessa narrativa um espaçamento. $\mathrm{O}$ termo diz bem a dimensão de algo que não possui início e fim definidos. A literatura participa desse caráter. $\mathrm{O}$ espaçamento é um prolongar-se do espaço antes e depois dele mesmo; é ser outro a partir de si sem ser esse si; é o não-presente. Derrida parte da diferança e chega ao espaçamento, dois termos, como a literatura, de definição problemática, pois escapam e contestam a ideia de delimitação:

A diferança é o que faz com que o movimento da significação não seja possível a não ser que cada elemento dito 'presente', que aparece sobre a cena da presença, se relacione com outra coisa que não ele mesmo, guardando em si a marca do elemento passado e deixando-se já moldar pela marca de sua relação com o elemento futuro (...). É necessário que um intervalo o separe do que não é ele para que ele seja ele mesmo, mas esse intervalo que o constitui em presente deve, no mesmo lance, dividir o presente em si mesmo, cindindo assim, como o presente, tudo o que a partir dele se pode pensar, ou seja, todo o ente. Esse intervalo constituindo-se, dividindo-se, dinamicamente, é aquilo a que podemos chamar espaçamento. (DERRIDA, 1991, p. 45)

A linguagem, como espaçamento, salta para além de si e, 
contraditoriamente, afirma-se no silêncio. O que ela não diz é um dos seus traços. Em $O$ Ateneu, o leitor terá o seu desejo de saber pouco satisfeito; o narrador raramente responde os questionamentos daquele. Há os fatos enunciados: as intrigas entre Sérgio e Sanches, a ruptura inesperada com Bento Alves, os desvelos de Ângela para com os alunos do internato, as carícias de Ema em Sérgio. Sobre o prolongamento deles nada se diz. A leitura suscita indagações não respondidas: consumou-se o desejo dos dois amigos numa relação sexual? Ângela, além de insuflar, satisfazia os anseios dos alunos? Ema foi com Sérgio além do acolhimento materno? Como explicar o seu desaparecimento? Explicitar essas questões ao leitor é pouco significativo, pois a obra inclui o espaçamento - "pausa, branco, pontuação, intervalo em geral” (DERRIDA, 1999, p. 83) - e requisita ao leitor que interaja com ele.

Lúcia Miguel Pereira distancia a obra de Pompéia do Naturalismo. Nessa obra, há o incêndio, a maldade e as imbricações entre o espaço e as ações das personagens, presenças que levam Mário de Andrade, em direção oposta, a contestar que O Ateneu seja "o menos naturalista dos romances do Naturalismo" (ANDRADE, 1974, p. 184). O predomínio, contudo, é dos hiatos, das desconstruções irônicas e das denúncias de hipocrisias. Isso leva Lúcia Miguel a aproximar o autor, por um lado, dos simbolistas e, por outro, de Machado de Assis e Flaubert. Em Pompéia, como em Flaubert, os acontecimentos dão lugar ao trabalho da linguagem. No caso de $O$ Ateneu, já se conjeturou que o texto "não constitui um enredo" entendido como "a tessitura dramática oriunda de um argumento" (CANDIDO \& CASTELLO, 1964, p. 268). Nesse sentido, há um quê do livro sobre o nada, tão almejado por Flaubert, nessa obra. O tédio do espaço atinge o narrador; é um miasma que contagia a narração e não busca urdir explicações, embora, para o leitor, essa possibilidade permaneça implícita.

Em Flaubert como em Pompéia, está-se dentro da literatura, sem, contudo, ser possível dizer o ser da literatura. Lendo as obras, encontram-se nelas o arranjo e o rearranjo da linguagem. Não é suficiente dizer que ambas as obras são literárias pelo seu 
caráter ficcional a despeito do viés autobiográfico apontado na de Pompéia. Ficcionalidade ou teor autobiográfico não são garantias da afirmação ou do distanciamento do literário. Inexiste para explicitar esse espaço um protocolo, uma gramática. Firmou-se ser a leitura elemento imprescindível para tangenciar-se o literário. Isso só se assenta; no entanto, se a leitura e o leitor confirmam o espaço da literatura no ato. Para que eles a afirmem nesse viés performativo em que a ação garante o objeto, é necessário, entretanto, que a linguagem permita esse reconhecimento, ou seja, que o texto lido junte-se, na sua potencialidade, a esse exercício. Parece paradoxal que não exista um protocolo, uma cartilha que afirme o ser da literatura, que não seja simplesmente a voz do leitor a garantia desse ser e, não obstante, afirmem-se ser o ato da leitura e o ser da linguagem os elementos permissivos do espaço literário. Aparentemente, caminha-se para aquilo de que se quis distanciar, ou seja, um encaixe que permita reconhecer na linguagem, por meio do leitor, o ser da literatura.

Isso se dá apenas aparentemente. O incipit da obra $O$ Ateneu e o do romance Madame Bovary não são modelos; são possibilidades. O mesmo pode ser dito da cronotopia bakhtiniana que une o espaço ao tempo, vincula a história ao texto literário, mas manifesta-se de modo singular a cada obra. Como já se disse não há um protocolo para definir o literário. O espaçamento explicita o ser movediço da literatura. A linguagem literária como o espaçamento não se firma numa presença, não se deixa delimitar; ela é em movimento, realiza-se nos constantes deslocamentos que impõe à linguagem e aos modos de narrar. A dimensão histórica e cultural, a intertextualidade, a ironia, os hiatos, todos esses elementos atravessam a literatura; nenhum deles, entretanto, diz o seu ser. Ela constitui-se não apenas no entrelaçamento do leitor e da linguagem, mas no exercício de uma linguagem que é, constantemente, uma promessa, um vir a ser. Pensar o ser da literatura é pensar um ser em trânsito - o sendo -, que absorve o passado, prenuncia o futuro e ao mesmo tempo 
distancia-se deles, inscrevendo a instabilidade no interior da pseudoestabilidade da linguagem.

\section{Referências}

ALIGHIERI, Dante. A divina comédia. São Paulo: Círculo do Livro/ Nova Cultural, [s.d.].

ANDRADE, Mário de. Aspectos da literatura brasileira. São Paulo: Martins, 1974.

BAKHTIN. Mikhail. Questões de literatura e de estética. São Paulo: Ed. da UNESP, 1993.

BARTHES, Roland. Como viver junto. São Paulo: Martins Fontes, 2003. BLANCHOT, Maurice. O espaço literário. Rio de Janeiro: Rocco, 2011. CANDIDO, Antônio; CASTELLO, José Aderaldo. Presença da literatura brasileira. São Paulo: Difusão Europeia do Livro, 1964.

CASTELLO, Luis A.; MÁRSICO, Cláudia T. Oculto nas palavras. Belo Horizonte: Autêntica, 2007.

DERRIDA, Jacques. Margens da filosofia. Campinas: Papirus, 1991.

DERRIDA, Jacques. Gramatologia. São Paulo: Perspectiva, 1999.

FLAUBERT, Gustave. Madame Bovary. São Paulo: Nova Cultural, 2002. FREUD, Sigmund. Delírios e sonbos na Gradiva de Jensen. Rio de Janeiro: Imago, 2003.

MIGUEL PEREIRA, Lúcia. Prosa de ficção (de 1870 a 1920). Rio de Janeiro: José Olympio, 1957.

POMPÉIA, Raul. O Ateneu. São Paulo: Abril Cultural, 1981.

SAINT-PIERRE, Bernardin de. Paul et Virginie. Paris: Bookking International, 1993.

Recebido para publicação em 29 de fevereiro de 2012 Aprovado em 30 de março de 2012 